\title{
Educação étnico-racial na escola: uma proposta em diálogo
}

\section{Ethnic-racial education in school: A proposal in dialogue}

Valéria Gonçalves Poleto é pós-graduanda pelo curso Master em Gestão Escolar: Administração e Supervisão da Universidade Anhembi Morumbi.

Contato: valeria.poleto@hotmail.com

\section{Resumo}

Nas últimas décadas, a preocupação dispensada ao preconceito e à discriminação que ocorrem com as crianças negras dentro e fora do ambiente escolar vem ocasionando ações que convergem no sentido de uma reparação dessas situações. 0 movimento negro tem se empenhado em conseguir uma postura reparativa do governo, concretizada, inicialmente, com a promulgação da lei 10.639/03. A escola, enquanto espaço de construção do conhecimento e de socialização, necessita organizar seu currículo e sua prática educativa de forma a valorizar a influência da cultura negra na história brasileira, garantindo que a criança possa formar sua identidade privada de visões preconceituosas e estereotipadas da cultura negra. 0 presente artigo procura fazer uma reflexão sobre a lei 10.639/03, sua aplicabilidade no currículo escolar e sua relevância no processo de construção da identidade da criança. Palavras-chave: Educação étnico-racial. Práticas Pedagógicas. Formação de identidade.

\begin{abstract}
In recent decades, the concern towards prejudice and discrimination that occur with afro-descendent children inside and outside school has led a movement to repair these situations. The afro-descendent movement has struggled for a restorative posture from the government, achieved initially through the enactment of Law 10.639/03. The school, as an area of knowledge construction and socialization, needs to organize their curriculum and their educational practice in order to valorize the influence of afro-descendent culture in Brazilian history, ensuring that the child can form their identity private stereotyped and prejudiced views of afro-
\end{abstract}


descendent culture. This article seeks to reflect on the law 10.639/03, its applicability in school curriculum and its relevance in the process of building the child's identity. Keywords: Ethnic-racial Education. Pedagogical Practices. Identity formation.

\section{Introdução}

Nos últimos anos, muitas discussões foram levantadas sobre o preconceito e a discriminação e, no que tange ao cenário escolar brasileiro, de como as crianças negras têm encontrado dificuldades em obter sucesso nos estudos e nas relações humanas estabelecidas dentro e, consequentemente, fora da escola. 0 governo, pressionado por movimentos sociais, em especial o movimento negro, vem organizando políticas públicas, chamadas de ações afirmativas, que têm por objetivo repensar e reorganizar o currículo escolar no que tange à educação étnico-racial e à importância do reconhecimento da cultura afrodescendente na história.

Um dos passos mais importantes e de maior efetividade do governo federal para concretizar essas ações foi a promulgação, em 09 de janeiro de 2003, da lei $n^{0} 10.639$, que altera a lei $n^{\circ}$ 9.394, de 20 de dezembro de 1996, estabelecendo as Diretrizes e Bases da Educação Nacional, para incluir no currículo oficial da rede de ensino a obrigatoriedade da temática "História e cultura Afro-Brasileira". Dessa forma, fica garantida por lei a obrigatoriedade da inclusão dessa temática no currículo das escolas brasileiras.

Essa nova demanda de organização do currículo fez com que as secretarias municipais de educação e as escolas se mobilizassem quanto à formação de professores/as e à confecção de materiais didáticos de apoio.

Pretende-se, neste artigo, ponderar sobre o papel da escola na formação do cidadão e, em especial, na formação da identidade étnico-racial, de forma que os/as protagonistas do processo de ensino e aprendizagem possam refletir sobre a importância dessa influência na historicidade brasileira e na formação da identidade da criança, transformando a escola em um espaço democrático e favorecendo a convivência igualitária. 


\section{Políticas reparadoras: a lei 10.639/03 e suas implicações}

Por muitos anos, a educação não foi considerada uma prioridade política, não existindo uma organização sistematizada e centrada na criança e em suas necessidades, nem tampouco fazendo alusão ao seu caráter obrigatório e gratuito, garantido por meio da Constituição Federal de 1988 (art. 206, 208).

A educação, desde o período colonial, nunca favoreceu as classes sociais mais desprovidas de recursos, excluindo dela indígenas, negros, pobres e escravizados. Por muito tempo, esses grupos sociais sofreram "danos psicológicos, materiais, sociais, políticos e educacionais" (CNE/CP 003, 2004, p. 3). A escola servia exclusivamente a uma elite que possuía condições de acesso à ela.

Com a promulgação da lei 10.639, em 09 de janeiro de 2003, deixa-se evidente que cabem ao Estado e à sociedade tomar

\footnotetext{
medidas para ressarcir os descendentes de africanos negros [...] em virtude das políticas explícitas ou tácitas de branqueamento da população, de manutenção de privilégios exclusivos para grupos com poder de governar e de influir na formulação de políticas, no pós-abolição (CNE/CP 003, 2004, p. 3).
}

Essa lei altera a Lei de Diretrizes e Bases da Educação Nacional, que foi promulgada em 20 de dezembro de 1996 ( $n^{\circ}$ 9394/96), em seu artigo 26-A, estabelecendo a obrigatoriedade do ensino de história e cultura afro-brasileira e africana no currículo oficial da rede de ensino brasileira. Representa a síntese das discussões predominantes nessa temática em nível nacional, promovendo um direcionamento às unidades escolares para o acréscimo e a manutenção da cultura afro-brasileira e suas origens no currículo e na prática educativa, favorecendo a política de reparações pretendida pelo governo (CNE/CP 003, 2004, p. 3), de modo a enfrentar os racismos e as exclusões, como uma forma de buscar a igualdade de oportunidade a todos os cidadãos, indiferentemente de sua origem étnico-racial.

A aprovação dessa Lei decorre de uma série de demandas do Movimento Social Negro Brasileiro e aponta para um novo momento das relações do Estado com os movimentos sociais organizados e a Educação (SME/DOT, 2008, p. 16). 
Esse movimento, no âmbito legislativo, permitiu ressignificar as práticas educativas no que concerne à valorização da imagem da população negra e reconhecer suas contribuições para a história cultural do Brasil. Dessa forma, essa lei tem favorecido a inserção dos estudos de história da África, "da luta das pessoas negras no Brasil e de sua presença na formação da nação brasileira" (SME/DOT, 2008, p. 16), constituindo-se em uma das principais iniciativas da política de reparações e ações afirmativas do governo.

\footnotetext{
[...] tais políticas têm, também, como meta o direito dos negros, assim como de todos cidadãos brasileiros, cursarem cada um dos níveis de ensino, em escolas devidamente instaladas e equipadas, orientados por professores qualificados para o ensino das diferentes áreas de conhecimentos; com formação para lidar com as tensas relações produzidas pelo racismo e discriminações, sensíveis e capazes de conduzir a reeducação das relações entre diferentes grupos étnico raciais, ou seja, entre descendentes de africanos, de europeus, de asiáticos, e povos indígenas (CNE/CP 003, 2004, p. 2).
}

Com essa lei, inicia-se um movimento na área educacional, mesmo que lento, que busca valorizar a diversidade cultural e as relações entre a educação e a comunidade escolar, favorecendo a democracia, a cidadania, o reconhecimento e o respeito à pluralidade cultural. Pressupõe-se, dessa forma, que a escola, enquanto espaço de socialização e de aprendizagens, "inaugura um novo caminho, já que a educação plural implica o repensar do ensino-aprendizagem" (SME/DOT, 2008, p. 17).

Como complemento à lei 10.639/03, foi homologada em 17 de junho de 2004 a Resolução CNE/CP n ${ }^{\circ}$, que institui as diretrizes curriculares nacionais para a educação das relações étnico-raciais e para o ensino de história e cultura afro-brasileira e africana. Essa Resolução busca cumprir o estabelecido na Constituição Federal e na LDBN (Lei de diretrizes e bases da Educação Nacional), que asseguram o direito ao acesso às diferentes fontes de culturas e histórias que compõem a cultura nacional brasileira.

Essas diretrizes vêm somar-se aos esforços da escola em adequar os propósitos educacionais apontados pela lei 10.639/03 ao currículo escolar, orientando 
Esse movimento governamental em prol da população negra deixa evidente que a política de reparações é um conjunto de ações que emergiram dos movimentos realizados por afrodescendentes pelo direito de se reconhecerem na cultura nacional, de garantirem a valorização de suas identidades, além de ter também "como meta o direito dos negros, assim como de todos os cidadãos brasileiros, cursarem cada um dos níveis de ensino, em escolas devidamente instaladas e equipadas" (CNE/CP n ${ }^{\circ}$ 003/2004, p. 2).

Essa decisão política desencadeou consequências pedagógicas na formação docente. Não basta garantir educação para todos, é necessário dar o devido valor à história cultural do povo brasileiro, que está intrinsecamente ligada à história dos negros e descendentes de africanos.

0 movimento iniciado no cenário legislativo, que visa à valorização e ao respeito às pessoas negras, bem como sua cultura e história, atende a uma demanda exigida pelo movimento social negro há décadas, que de imediato deve ser respeitado e executado por toda a sociedade civil e educacional.

\section{A escola como instrumento de inserção e transformação}

A escola é um dos lugares onde a criança constrói sua identidade, concebida pelas trocas estabelecidas com outras crianças oriundas de situações sociais diversas. Por conta disso, a escola pode se tornar o primeiro espaço de vivência do racismo e do preconceito.

Local de descobertas e aprendizagens, é na escola que se desenvolvem conceitos de viver e conviver em grupo. A relação entre crianças brancas e negras pode se tornar problemática caso não haja uma intervenção do educador, possibilitando situações de rejeição ou de constrangimento em relação às crianças negras, ou até mesmo situações de isolamento (GONÇALVES, 1985 apud LIMA, 2006, p. 146).

Sodré (1983, apud LIMA, 2006, p. 142) enfatiza a importância do reconhecimento social na construção da identidade dos sujeitos, destacando sua relevância para a positivação do "eu", o fortalecimento da autoestima e do desenvolvimento da explicitação do "nós". Dessa forma, as identidades "são imbricadas na semelhança a si próprio, na identificação com o outro e estão no contexto das relações sociais; [...] construídas com base em repertórios culturais históricos" (LIMA, 2006, p. 143). Nesse 
sentido, o papel da escola torna-se primordial, pois esta precisa estar bem preparada para acolher a pluralidade étnica e cultural da criança e do meio que a cerca, de forma a desenvolver a capacidade de questionar, para que tenha consciência de sua identidade e de qual grupo se insere. É através dessa consciência que a criança começará o processo de construção de sua própria identidade.

Entretanto, se a escola e o educador omitem o conhecimento acerca dessa pluralidade étnica e cultural, desprestigiando as raízes históricas brasileiras imbricadas nas raízes africanas e afins, torna dificultoso para a criança, em especial a negra, a construção de sua identidade e, consequentemente, a valorização dela por todos que fazem parte desse contexto educacional (VALENTE, 1995). Por conta desse déficit no currículo, pode surgir no cenário educacional o processo de exclusão e o de incorporação do preconceito, que será posteriormente refletido no âmbito social.

\section{Quanto a isso, a Resolução CNE/CP n 003 afirma que}
[...] sistemas de ensino e estabelecimentos de diferentes níveis converterão as demandas dos afro-brasileiros em políticas públicas do Estado ou institucionais [...] medidas estas coerentes com um projeto de escola, de educação, de formação de cidadãos que explicitamente se esbocem nas práticas pedagógicas cotidianas. Medidas que, convém, sejam compartilhadas pelos sistemas de ensino, processos de formação de professores, comunidade, professores, alunos e seus pais (2004, p. 4).

Assim, percebe-se a emergência de uma mudança no currículo escolar, além de programas para formação de professores, com o intuito de subsidiar e aperfeiçoar suas práticas educativas no que concerne à história e à cultura afro-brasileira. A lei necessita ser cumprida nas instituições de ensino públicas e privadas, pois ambas possuem o mesmo objetivo comum. 0 cumprimento dessa medida engloba mudanças no currículo, nas práticas aplicadas cotidianamente e, principalmente, na forma de se pensar e encarar a história e a cultura afro-brasileiras. As escolas necessitam subsidiar as condições para a concretização dessas medidas e formular instrumentos que avaliem a eficácia de suas ações.

Garantia, pelos sistemas de ensino e entidades mantenedoras, de condições humanas, materiais e financeiras para execução de projetos com o objetivo de Educação das Relações Étnico-raciais e estudo de História e Cultura Afro-Brasileira e Africana, assim como organização de serviços e atividades que controlem, avaliem e redimensionem sua consecução, que exerçam fiscalização das políticas adotadas e providenciem correção de distorções (CNE/CP n ${ }^{0} 003 / 2004$, p. 15). 
As Secretarias de Educação têm se preocupado com a aplicabilidade da lei nas escolas públicas, mesmo que seja ainda de forma embrionária. 0 mesmo não se pode dizer das instituições de ensino privadas, pois não há como aferir a aplicabilidade da lei em suas práticas educativas, por falta de instrumentos avaliativos oriundos da esfera governamental. Essa falta de instrumentalização avaliativa dificulta a fiscalização. Dessa forma, o cumprimento da lei é "responsabilidade de todos, e não apenas do professor em sala de aula", o que exige "um comprometimento solidário dos vários elos do sistema de ensino brasileiro" (CNE/CP $\mathrm{n}^{\circ} 003 / 2004$, p. 16).

Para o êxito das políticas públicas de reparações, a escola precisa transformar-se em um espaço onde as diferenças possam ser trabalhadas, subsidiando ações de diminuição e prevenção da exclusão social, do preconceito e do racismo comumente aplicados à criança negra. Nesse sentido, é evidente que a importância de uma educação que respeite e valorize a cultura das diferentes famílias atendidas, em um ambiente no qual se instale o frequente diálogo acerca do desafio do respeito à diversidade.

A incorporação da história e da cultura afro-brasileiras pela prática educativa escolar se constitui em um grande desafio para o professor que, sem a formação devida, pode contribuir para a afirmação ou a negação das identidades étnico-raciais e, consequentemente, para a superação ou legitimação da discriminação e do preconceito.

A escola age de forma pontual na internalização de valores universalmente concebidos e na construção da identidade dos que dela têm acesso, permanecendo no foco da discussão sobre as questões étnico-raciais, já que foi por meio dela que, durante séculos, se mantiveram legitimadas práticas de discriminação e preconceito, seja pelo discurso proferido ou pelo material didático inapropriado, por omissão de informação, ou por estereótipos vexatórios à população negra. A escola traz ainda, segundo Cavalleiro (2000, p. 197), "infinitas possibilidades para a interiorização de comportamentos e atitudes preconceituosas e discriminatórias contra o negro".

Dessa forma, cabe à instituição escolar reformular e readequar o seu currículo, de forma a possibilitar a todos que fazem parte do seu contexto o conhecimento e a valorização da cultura afrobrasileira, que vai além da escravidão, como apresentado em muitos livros. 


\section{Considerações Finais}

Ao longo da história da educação brasileira evidencia-se uma evolução paulatina no que diz respeito ao acesso e permanência das crianças na escola, em especial das crianças negras. 0 acesso não garante a qualidade, bem como não garante a equidade das ações docentes no que se refere ao ensino da cultura afrobrasileira, que deveria ser inerente aos currículos escolares.

Sua raiz histórica, que deveria ser orgulho para os cidadãos brasileiros, indiferentemente de sua cor de pele, etnia ou religião, necessita de uma força maior - a lei - para que possa ser oportunizada nas escolas enquanto saber essencial para a formação da identidade da criança e para a construção do conhecimento. Nesse sentido, realmente foi uma vitória dos movimentos negros a promulgação da lei 10.369/03.

Mesmo com instrumentos reguladores e norteadores (as leis, os pareceres e as resoluções), essa nova prática educativa necessitaria de um dispositivo avaliador que pudesse verificar em que medida essas políticas públicas têm sido aplicadas no cotidiano escolar. Segundo os documentos oficiais, as escolas deveriam ter os seus próprios instrumentos avaliativos, mas acredito que um instrumento avaliativo oriundo da esfera governamental facilitaria a verificação da aplicabilidade da lei tanto na escola pública, quanto na privada. Devido à ausência de instrumentos de avaliação, encontra-se certa dificuldade em monitorar o cumprimento da lei nas escolas.

É evidente que o preconceito e a discriminação não acontecem somente no cenário educativo. Mas, enquanto espaço de aprendizagens e de formação de cidadãos críticos, a escola, no que diz respeito à organização do currículo, necessita estar preparada para lidar com tais situações. A partir da valorização da cultura afro-brasileira, poderemos abrir nossos olhares para o respeito a toda e qualquer forma de expressão cultural que existe dentro das nossas escolas. Nesse sentido, não é pretensão da lei impor uma cultura em detrimento de outra, e sim abrir o debate sobre como devemos cuidar para que a educação não favoreça esse ou aquele conhecimento. Os/as professores/as, por sua vez, devem ser conscientes das consequências de seus atos e devem estar sempre atualizados e preparados para lidar com as situações cotidianas e com a diversidade cultural presente nas salas de aula. 


\section{REFERÊNCIAS}

BRASIL. Parecer CNE/CP n ${ }^{\circ}$ 003, de 10 de março de 2004. Institui as Diretrizes Curriculares Nacionais para a Educação das Relações Étnico-Raciais e para o Ensino de História e Cultura Afro-Brasileira e Africana. Disponível em: <http:// portal.mec.gov.br/cne/arquivos/pdf/003.pdf>. Acesso em: 05 set.2013.

BRASIL. Resolução CNE/CP n 1, de 17 de junho de 2004. Institui as Diretrizes Curriculares Nacionais para a Educação das Relações Étnico-Raciais e para o Ensino de História e Cultura Afro-Brasileira e Africana. Disponível em: <http:// portal.mec.gov.br/cne/arquivos/pdf/res012004.pdf>. Acesso em: 05 set. 2013.

BRASIL. Lei no 10.639/03, de 09 de janeiro de 2003. Altera a lei 9394/96, que estabelece as diretrizes e bases da educação nacional, para incluir no currículo oficial da Rede de Ensino a obrigatoriedade da temática "História e Cultura Afro-Brasileira". Disponível em: <http://www. planalto.gov. br/ccivil_03/leis/2003/l10.639.htm>. Acesso em: 07 set. 2013.

CAVALLEIRO, Eliane dos Santos. Do silêncio do lar ao silêncio escolar: racismo, preconceito e discriminação na educação infantil. São Paulo: Contexto, 2000.

LIMA, Maria Batista. Identidades étnico-raciais, infância afro-brasileira e práticas escolares. In: ROCHA, Eloisa A. C.; KRAMER, Sonia (Orgs.). Educação infantil: enfoques em diálogo. Campinas: Papirus, 2011. p.139 - 155.

SÃO PAULO (SME/DOT). 2008. Orientações Curriculares: expectativas de aprendizagem para a educação étnico-racial na educação infantil, ensino fundamental e médio. Disponível em: <http://arqs. portaleducacao.prefeitura.sp.gov.br/exp/ educacaoetnicoracial.pdf>. Acesso em: 05 set. 2013.

VALENTE, Ana Lucia E. F. Proposta metodológica de combate ao racismo nas escolas. Disponível em: <http://educa.fcc. org.br/pdf/cp/n93/n93a05.pdf>. Acesso em: 20 out. 2013.

Recebido em: 25/07/2014

Revisto em: 24/09/2014

Aprovado em: 26/09/2014 